\title{
Asymptomatic Middle East Respiratory Syndrome coronavirus infection using a serologic survey in Korea
}

\author{
Yeong-Jun Song ${ }^{1 *}$, Jeong-Sun Yang ${ }^{2 *}$, Hee Jung Yoon ${ }^{3}$, Hae-Sung Nam ${ }^{4}$, Soon Young Lee ${ }^{5}$, \\ Hae-Kwan Cheong ${ }^{6}$, Woo-Jung Park ${ }^{2}$, Sung Han Park², Bo Youl Choi ${ }^{7}$, Sung Soon Kim², Moran Ki \\ 'Department of Cancer Control and Population Health, Graduate School of Cancer Science and Policy, National Cancer Center, Goyang, \\ Korea; ${ }^{2}$ Korea National Institute of Health, Korea Centers for Disease Control and Prevention, Cheongju, Korea; ${ }^{3}$ Korean Society of Infectious \\ Diseases, Seoul, Korea; ${ }^{4}$ Department of Preventive Medicine and Public Health, Chungnam National University School of Medicine, Daejeon, \\ Korea; ${ }^{5}$ Department of Preventive Medicine and Public Health, Ajou University School of Medicine, Suwon, Korea; ${ }^{6}$ Department of Social and \\ Preventive Medicine, Sungkyunkwan University School of Medicine, Suwon, Korea; ${ }^{7}$ Department of Preventive Medicine, Hanyang University \\ College of Medicine, Seoul, Korea
}

OBJECTIVES: The rates of asymptomatic infection with Middle East Respiratory Syndrome (MERS) coronavirus vary. A serologic study was conducted to determine the asymptomatic MERS infection rate in healthcare workers and non-healthcare workers by exposure status.

METHODS: Study participants were selected from contacts of MERS patients based on a priority system in 4 regions strongly affected by the 2015 MERS outbreak. A sero-epidemiological survey was performed in 1,610 contacts (average duration from exposure to test, 4.8 months), and the collected sera were tested using an enzyme-linked immunespecific assay (ELISA), immunofluorescence assay (IFA), and plaque reduction neutralization antibody test (PRNT). Among the 1,610 contacts, there were 7 ELISA-positive cases, of which 1 exhibited positive IFA and PRNT results.

RESULTS: The asymptomatic infection rate was $0.060 \%$ (95\% confidence interval, 0.002 to 0.346 ). The asymptomatic MERS case was a patient who had been hospitalized with patient zero on the same floor of the hospital at the same time. The case was quarantined at home for 2 weeks after discharge, and had underlying diseases, including hypertension, angina, and degenerative arthritis.

CONCLUSIONS: The asymptomatic infection was acquired via healthcare-associated transmission. Thus, it is necessary to extend serologic studies to include inpatient contacts who have no symptoms.

KEY WORDS: Asymptomatic infection, Epidemiology, Middle East Respiratory Syndrome coronavirus, Nosocomial infections, Outbreak, Enzyme-linked immunespecific assay

\section{Correspondence: Moran Ki}

Department of Cancer Control and Population Health, Graduate School of Cancer Science and Policy, National Cancer Center,

323 Ilsan-ro, Ilsandong-gu, Goyang 10408, Korea

E-mail:moranki@ncc.re.kr

*Song \& Yang contributed equally to this work as joint first authors. Received: Mar 26, 2018 / Accepted: Apr 15, 2018 / Published: Apr 15, 2018

This article is available from: http://e-epih.org/

(C) This is an open-access article distributed under the terms of the Creative Commons Attribution License (http://creativecommons.org/licenses/by/4.0/), which permits unrestricted use, distribution, and reproduction in any medium, provided the original work is properly cited.

(C) 2018, Korean Society of Epidemiology

\section{INTRODUCTION}

Middle East Respiratory Syndrome (MERS) is a severe respiratory infection caused by a novel beta coronavirus (MERS-CoV) [1-3]. The symptoms of MERS include fever, chills, cough, shortness of breath, gastrointestinal symptoms, expectoration, wheezing, chest pain, hemoptysis, sore throat, headache, myalgia, abdominal pain, vomiting, and diarrhea; it can also cause death in severe cases [3-6].

The causative pathogen of MERS is transmitted via 4 modes: animal-to-human, intra-familial, healthcare-associated, and travel-related $[7,8]$. The 186 cases that occurred in South Korea (hereafter Korea) were predominantly caused by healthcare-associated 
transmission [7,9-11], followed by intra-familial transmission.

According to data reported to the World Health Organization, the rates of asymptomatic or mild infection were 44 of 398 (28.60\%) in Saudi Arabia, the United Arab Emirates, and the Islamic Republic of Iran between April and June 2014, and 32 of 113 (28.31\%) in Saudi Arabia in June 2014 [12,13]. However, Oboho et al. [14] reported that $78.79 \%$ (26 of 33) of initially reported asymptomatic patients had at least 1 symptom. In Korea, among the 186 confirmed cases, 3 asymptomatic cases were detected among healthcare workers via screening tests (1.61\%) [15]. In serologic studies using indirect immunofluorescence tests for healthcare workers who were at MERS-affected hospitals, 2 of 457 (0.44\%) had positive results [16]. However, no report has been published regarding the asymptomatic infection rate among non-healthcare workers in Korea. There is a considerable chance of human-to-human transmission, as well as direct infection via the dromedary camel [17-19]. Therefore, it is necessary to identify the rate of asymptomatic MERS infections in healthcare workers and non-healthcare workers.

\section{MATERIALS AND METHODS}

\section{Selection and participation of individuals}

This survey was conducted between August 2015 and February 2016 after the last MERS case diagnosed in July 5, 2015. Based on a database of quarantined individuals provided by the Department of Epidemiologic Investigation of the Korea Centers for Disease Control and Prevention (KCDC), individuals from 4 regions with major outbreaks-Seoul, Gyeonggi, Chungcheong, and Jeonbuk -were selected. Individuals whose MERS status was diagnosed as positive using a polymerase chain reaction test were excluded from the analysis of this study. From the 14,831 quarantined individuals, 7,233 residents (48.8\%) living in the 4 major MERS outbreak regions were selected. Of these individuals, calls requesting participation in this study were made to 3,291 individuals (45.5\%) according to prioritization groupings. A total of 1,610 individuals (48.9\%) ultimately participated in the study (Figure 1 ). Those who refused to participate have been described in another study [20].

The study individuals were prioritized in groups according to the transmission intensity of the MERS case they were exposed to, as follows: contact with super-spreading events (5 or more individuals infected) [21], contact with spreaders who infected 1 to 4 individuals, and contact with non-spreaders. We selected study subjects according to this prioritization of groups, and the selection rates were $48.8,16.4$, and $15.8 \%$, respectively. We also categorized the subjects according to their exposure intensity (i.e., status when they were exposed to the MERS case), as follows: inpatients or outpatients at a MERS-affected hospital, cohabiting family members or paid caregivers of the MERS case, visitors of the hospitalized MERS case, healthcare workers employed at a MERS-affected hospital, and colleague of the MERS case. We selected more subjects from the categories of family, patients, and visitors (Table 1).

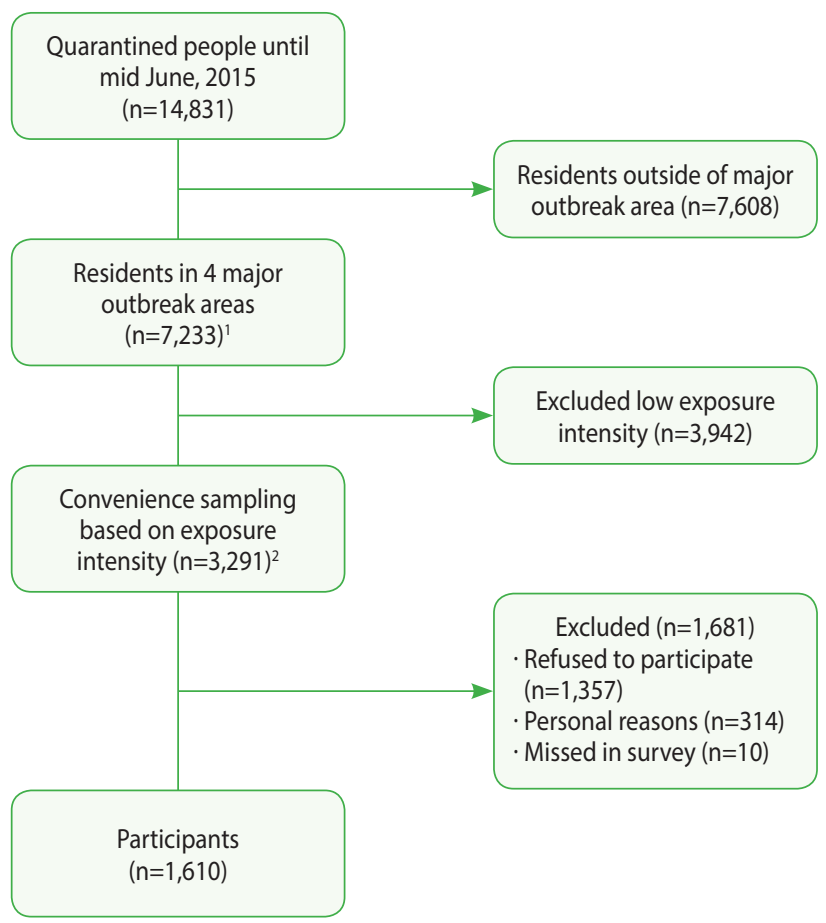

Figure 1. Flowchart of participants in the Middle East Respiratory Syndrome (MERS) serologic survey in Korea. 'Major MERS outbreak areas including Seoul, Gyeonggi, Chungcheong, and Jeonbuk in Korea. ${ }^{2}$ Selection rates were different by characteristics of exposed MERS case and status of subjects (see the Table 1).

\section{Study performance}

Only individuals who consented to participate in the study through a telephone call and gave written consent at the time of study initiation underwent surveys at local public health centers. Each participant responded to a questionnaire on exposure and provided a blood sample. Following the first serologic test by an enzymelinked immunospecific assay (ELISA), positive or borderline cases were tested using an immunofluorescence assay (IFA) and a plaque reduction neutralization antibody test (PRNT).

\section{Antibody tests}

MERS-CoV antibody levels in all sera collected from contacts were measured using a recombinant S1 protein-coated human anti-MERS-CoV (immunoglobulin G [IgG]) ELISA kit (Euroimmun, Luebeck, Germany), which was used according to the manufacturer's protocol. The results of the tested samples were determined by calculating the ratio of the optical density (OD) value of the sample to the OD value of the calibrator. Ratios $\geq 1.1$ were considered positive, ratios $\geq 0.8$ to $<1.1$ were considered borderline, and ratios $<0.8$ were considered negative.

IFA slides were coated with MERS-CoV non-infected or infected Vero cells. Serum samples were diluted in phosphate-buffered saline (PBS) to $1: 10,1: 100,1: 250$, and 1:1,000, transferred to IFA slides, and incubated for 30 minutes at $37^{\circ} \mathrm{C}$ in a humidified chamber. The IFA slides were washed 3 times in PBS-T for 5 minutes 
Table 1. Study subjects and seropositive participants by characteristics of the MERS case they were exposed to, and status of subjects upon MERS exposure in the 2015 Korean outbreak

\begin{tabular}{|c|c|c|c|c|c|c|c|c|c|}
\hline & \multirow{2}{*}{$\begin{array}{l}\text { Characteristics of } \\
\text { exposed MERS case }\end{array}$} & \multicolumn{7}{|c|}{ Status of subjects when they were exposed to MERS ${ }^{1}$} & \multirow{2}{*}{$\begin{array}{c}\text { Selection or } \\
\text { response rate } \\
(\%)^{2}\end{array}$} \\
\hline & & Patient & Family & Visitor & $\begin{array}{l}\text { Healthcare } \\
\text { worker }\end{array}$ & $\begin{array}{l}\text { Col- } \\
\text { league }\end{array}$ & $\begin{array}{l}\text { Un- } \\
\text { known }\end{array}$ & Total & \\
\hline \multirow{4}{*}{$\begin{array}{l}\text { Quarantined } \\
\text { subjects }\end{array}$} & Spreaders with 5 or more cases & 1,141 & 71 & 417 & 558 & 3 & 657 & 2,847 & \\
\hline & Spreaders with 1 to 4 cases & 1,067 & 64 & 364 & 198 & 35 & 375 & 2,103 & \\
\hline & Non-spreaders & 3,489 & 321 & 1,613 & 1,260 & 453 & 2,745 & 9,881 & \\
\hline & Total & 5,697 & 456 & 2,394 & 2,016 & 491 & 3,777 & 14,831 & \\
\hline \multirow{5}{*}{ Selected subjects } & Spreaders with 5 or more cases & 744 & 60 & 254 & 115 & 3 & 212 & 1,388 & 48.8 \\
\hline & Spreaders with 1 to 4 cases & 191 & 10 & 105 & 10 & 0 & 29 & 345 & 16.4 \\
\hline & Non-spreaders & 626 & 101 & 281 & 184 & 101 & 265 & 1,558 & 15.8 \\
\hline & Total & 1,561 & 171 & 640 & 309 & 104 & 506 & 3,291 & 22.2 \\
\hline & Selection rate (\%) & 27.4 & 37.5 & 26.7 & 15.3 & 21.2 & 13.4 & 22.2 & \\
\hline \multirow{5}{*}{$\begin{array}{l}\text { Study partici- } \\
\text { pants }\end{array}$} & Spreaders with 5 or more cases & 252 & 53 & 152 & 94 & 1 & 0 & 552 & 39.8 \\
\hline & Spreaders with 1 to 4 cases & 60 & 4 & 62 & 12 & 0 & 1 & 139 & 40.3 \\
\hline & Non-spreaders & 262 & 109 & 271 & 201 & 50 & 26 & 919 & 59.0 \\
\hline & Total & 574 & 166 & 485 & 307 & 51 & 27 & 1,610 & 48.9 \\
\hline & Response rate (\%) & 36.8 & 97.1 & 75.8 & 99.4 & 49.0 & 5.3 & 48.9 & \\
\hline \multirow{5}{*}{$\begin{array}{l}\text { Subjects with } \\
\text { seropositive } \\
\text { ELISA (IFA/ } \\
\text { PRNT) }\end{array}$} & Spreaders with 5 or more cases & $2(1)$ & & & $1(0)$ & & & $3(1)$ & \\
\hline & Spreaders with 1 to 4 cases & $1(0)$ & & & & & & $1(0)$ & \\
\hline & Non-spreaders & $3(0)$ & & & & & & $3(0)$ & \\
\hline & Total & $6(1)$ & & & $1(0)$ & & & $7(1)$ & \\
\hline & Seropositive rate (\%) & $1.05(0.17)$ & & & $0.33(-)$ & & & $0.43(0.06)$ & \\
\hline
\end{tabular}

MERS, Middle East Respiratory Syndrome; ELISA, enzyme-linked immunospecific assay; IFA, immunofluorescence assay; PRNT, plaque reduction neutralization antibody test.

'Inpatients or outpatients at a MERS-affected hospital, family of people living with or a paid caregiver of the MERS case, visitors of the hospitalized MERS case, healthcare workers employed at a MERS-affected hospital, and colleagues of co-workers of a MERS case.

${ }^{2}$ Selection rates varied by characteristics of the MERS case subjects were exposed to (i.e. transmission intensity) and the subjects' status (i.e. exposure intensity).

each and incubated with fluorescein isothiocyanate-conjugated rabbit anti-human IgG (Abcam, Cambridge, MA, USA) diluted at 1:800 for 30 minutes at $37^{\circ} \mathrm{C}$ in a humidified chamber. After washing 3 times in PBS-T for 5 minutes, the slides were embedded with a mounting fluid, topped with a cover glass, and observed under a fluorescent microscope.

The neutralizing antibodies in the serum samples were measured by PRNT. The PRNT procedures were performed as follows. In brief, 1:10 diluted sera were heat-inactivated at $56^{\circ} \mathrm{C}$ for $30 \mathrm{~min}$ utes. Heat-inactivated sera were diluted serially 4 -fold. After an equal volume of virus (MERS-CoV/KOR/KNIH/002_05_2015) was added to the volume of serum dilutions, these mixtures were incubated at $37^{\circ} \mathrm{C}$ for 2 hours. The mixtures were added to each well of the 24-well plate cultured with Vero cells. The plate was incubated at $37^{\circ} \mathrm{C}$ for 60 minutes, and $1 \mathrm{~mL}$ of $1.5 \%$ carboxymethylcellulose overlay medium was then added. After incubation for 3-4 days, cell staining was performed by crystal violet. The titer of neutralizing antibody by $\mathrm{PRNT}_{50}$ was calculated using the Kärber formula, as described previously [22]. A titer above 1:20 was interpreted as positive. All sera with a positive or borderline reaction in ELISA were tested by the IFA and PRNT assays for confirmation, and cases with positive results from any 2 assays were con- sidered to be anti-MERS positive.

This study received approval from the bioethics committee of the KCDC (2015-08-EXP-03-P-A) and the institutional review board of the National Cancer Center (NCC 2016-0058). Informed consent was obtained from study participants or their parent or legal guardian for children under 14.

\section{RESULTS}

Among the 3,291 selected individuals, the response rates of contacts with super-spreading events (5 or more individuals infected), contacts with spreaders who infected 1-4 individuals, and contacts with non-spreaders were $39.8 \%$ (552 of 1,388), $40.3 \%$ (139 of 345), and 59.0\% (919 of 1,558), respectively. According to their status when they were exposed to the MERS case, the highest response rates were found for healthcare workers (99.4\%), and family members $(97.1 \%)$, followed by visitors $(75.8 \%)$, colleagues (49.0\%), and patients (36.8\%) (Table 1 ).

The seropositive rate using ELISA was $1.05 \%$ (6 of 574) in patients, $0.33 \%$ ( 1 of 307 ) in healthcare workers, and $0.43 \%$ (7 of 1,610) overall. Among the 7 ELISA-positive individuals, 3 had contact with a super-spreading event (patient zero, case \#1) who 
Table 2. Characteristics of MERS-seropositive subjects by ELISA, IFA, and PRNT in Korea, 2015

\begin{tabular}{|c|c|c|c|c|c|c|c|c|c|c|}
\hline \multirow{2}{*}{$\begin{array}{l}\text { Subject } \\
\text { ID }\end{array}$} & \multirow{2}{*}{$\begin{array}{l}\text { Exposure } \\
\text { date }\end{array}$} & \multirow{2}{*}{$\begin{array}{l}\text { Sampling } \\
\text { date }\end{array}$} & \multirow{2}{*}{$\begin{array}{l}\text { Status at } \\
\text { exposure }\end{array}$} & \multirow{2}{*}{$\begin{array}{c}\text { Exposed } \\
\text { MERS case } \\
\text { ID }^{1}\end{array}$} & \multirow{2}{*}{$\begin{array}{l}\text { Underlying } \\
\text { disease }\end{array}$} & \multirow{2}{*}{$\begin{array}{l}\text { Symptoms } \\
\text { after exposure }\end{array}$} & \multicolumn{2}{|c|}{ ELISA } & \multirow[b]{2}{*}{ IFA } & \multirow[b]{2}{*}{ PRNT } \\
\hline & & & & & & & Ratio & Result & & \\
\hline 1 & May 15 & Nov 1 & Patient & $\# 1$ & Angina & None & 0.996 & Borderline & Positive & Positive \\
\hline 2 & May 16 & Nov 2 & Patient & $\# 1$ & None & None & 2.078 & Positive & Negative & Negative \\
\hline 3 & May 15 & Nov 2 & $\begin{array}{l}\text { Healthcare } \\
\text { worker }\end{array}$ & $\# 1$ & None & Fatigue & 1.640 & Positive & Negative & Negative \\
\hline 4 & Jun 9 & Oct 31 & Patient & $\# 118$ & Hypertension & Blurred vision & 1.116 & Positive & Negative & Negative \\
\hline 5 & Jun 4 & Nov 8 & Patient & $\# 89$ & $\begin{array}{l}\text { Hypertensive } \\
\text { heart disease }\end{array}$ & None & 0.916 & Borderline & Negative & Negative \\
\hline 6 & Jun 5 & Nov 9 & Patient & $\# 89$ & $\begin{array}{l}\text { Lumbar spinal } \\
\text { stenosis }\end{array}$ & Fatigue & 1.724 & Positive & Negative & Negative \\
\hline 7 & Jun 11 & Nov 8 & Patient & $\# 89$ & None & $\begin{array}{l}\text { Fatigue and } \\
\text { blurred vision }\end{array}$ & 0.985 & Borderline & Negative & Negative \\
\hline
\end{tabular}

MERS, Middle East Respiratory Syndrome; ELISA, enzyme-linked immunospecific assay; IFA, immunofluorescence assay; PRNT, plaque reduction neutralization antibody test.

'Patient zero (\#1) infected 28 cases (super-spreading event transmitting 5 or more cases), case \#118 infected 2 cases, and case \#89 did not transmit MERS to anyone during the 2015 Korean MERS outbreak.

infected 28 individuals [23], 1 had contact with a spreader (case \#118) who infected 2 individuals, and 3 had contact with a nonspreader (case \#89). Among the ELISA-positive individuals, only 1 was both IFA-positive and PRNT-positive. Therefore, the confirmed rates of asymptomatic MERS infection were $0.17 \%$ in patients and $0.060 \%$ (95\% confidence interval, 0.002 to 0.346 ) overall (Table 1).

The confirmed asymptomatic case, patient zero, and 11 secondary MERS patients were hospitalized on the same floor of the hospital at the same time $[23,24]$. The asymptomatic case was quarantined at home for 2 weeks after discharge. The case had underlying diseases that included hypertension, angina, and degenerative arthritis. The case reported no fever, cough, myalgia, or gastrointestinal symptoms during hospitalization or quarantine (Table 2).

\section{DISCUSSION}

Limited information exists regarding MERS-CoV seroprevalence among populations other than confirmed MERS cases. Saudi Arabian data showed that the seroprevalence of MERS-CoV IgG among the general population was $0.15 \%$ [25], suggesting that a number of cases of asymptomatic or mild infections may be present in the general population.

Despite a high prevalence of 186 confirmed MERS cases during the outbreak of MERS in Korea, the rate of asymptomatic infection (1.60\%) [15] was lower than expected. The rates of asymptomatic infection confirmed using IFA and PRNT in the present study were $0.06 \%$ ( 1 of 1,610 ) for all contacts and $0.17 \%$ ( 1 of 574 ) for patients. These results are markedly lower than the rates of $0.27 \%$ ( 2 of 737 ) among healthcare workers, and $0.44 \%$ ( 2 of 457 ) among healthcare workers at MERS-affected hospitals in Korea [16]. Moreover, the rate of asymptomatic or mild infection in Sau- di Arabia, the United Arab Emirates, and the Islamic Republic of Iran was approximately $28.00 \%[12,13,18]$.

The confirmed asymptomatic case presented in this study was a patient at the same hospital as confirmed MERS cases and, unlike in previous studies, was neither an intra-familial infection nor a pediatric infection $[26,27]$. The low rate of asymptomatic infection in Korea is attributable to the different transmission pathway of MERS infections compared to the Middle East. In Korea, most of the MERS cases were healthcare-associated infections, and none were from an animal. The low asymptomatic infection rate is also attributable to the extensive epidemiological investigation conducted in Korea, including close monitoring of contacts with MERS patients; this helped identify almost all MERS patients. This may also have been attributable to the promotion of proactive identification of patients via mass media and the establishment of communication networks by the government, leading to voluntary reports by people, active quarantine, and countermeasures to this public health crisis $[10,28,29]$.

ELISA is appropriate as a screening tool, as it is 10-fold more sensitive than IFA. However, it may cross-react with seasonal human coronavirus antibodies, so a spike protein-specific IFA is required for confirmation. PRNT is a definitive test when ELISA and IFA have inconclusive results [25]. Only 10\% of ELISA-positive results are positive on a neutralization assay [25]. In our study, 1 of 7 patients with borderline or positive ELISA results also had positive results in PRNT. Therefore, the results obtained in our study are accurate because ELISA, IFA, and PRNT were used.

A previous study predicted the pandemic potential of MERS$\mathrm{CoV}$ to be $\leq 5 \%$; however, this does not indicate that the risk has abated [30]. Prerequisites for reducing the risk include improved surveillance, active contact tracing, and the initiation of animal host searching [30,31]. During the outbreak in Korea, MERS was classified as a notifiable infectious disease and was subjected to 
surveillance [32]. Since MERS is an imported disease in Korea, it is recommended that precautions be taken before travel and that the time of returning from travel and incubation period be considered.

This study showed a low seropositivity in the population of individuals quarantined due to contact with MERS cases. However, there is a possibility that the seropositivity rate was underestimated for the following reasons. Firstly, the participants of the present study were mostly non-healthcare workers and were relatively healthy. Thus, the risk of infection was low. Secondly, the overall participation rate was $48.9 \%$, whereas it was $36.8 \%$ in the patient group at a higher risk of infection. Moreover, we only surveyed $10.9 \%$ of the quarantined individuals. Therefore, the actual rate of asymptomatic infections may be higher than reported in the present study. Lastly, the present study may have been conducted too late. In a previous study, MERS-CoV ELISA results indicated that the antibody response was highest after 3 weeks from symptom onset [33]. Although no reports have analyzed the duration of antibody presence in MERS patients regardless of symptoms, a recent study of severe acute respiratory syndrome and MERS reported that antibodies in some patients persisted for up to 2-3 years after infection $[34,35]$. Blood sampling for serologic test in this study was performed on contacts between October and December 2015, while exposure to the confirmed case occurred between May and June 2015 (a gap of 5 months). Thus, a loss of the MERS$\mathrm{CoV}$ antibody titer could have taken place despite actual asymptomatic infections; therefore, the actual rate of asymptomatic infection may be higher than the rate presented in this report.

In conclusion, among 1,610 contacts, only 1 non-healthcare worker who was a patient in a MERS-affected hospital had an asymptomatic MERS-CoV infection. To understand new emerging infectious diseases such as MERS, more intensive epidemiologic research is needed, including an analysis of asymptomatic infections.

\section{ACKNOWLEDGEMENTS}

The authors would like to thank Hee-Dong Jung and Jeong-Gu Nam (Korea Centers for Disease Control and Prevention) for laboratory assistance and technical support in production of the manuscript. Additionally, we would like to thank all the administrative and laboratory staff of the Korea Centers for Disease Control and Prevention who participated in the MERS-CoV outbreak control in Korea.

\section{CONFLICT OF INTEREST}

The authors have no conflicts of interest to declare for this study.

\section{ORCID}

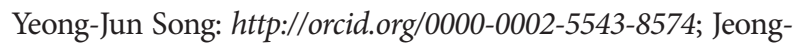
Sun Yang: http://orcid.org/0000-0001-5005-9738; Hee Jung Yoon: http://orcid.org/0000-0001-9860-4774; Hae-Sung Nam: http://orcid.org/0000-0003-0911-4576; Soon Young Lee: http://orcid.org/ 0000-0002-3160-577X; Hae-Kwan Cheong: http://orcid.org/00000003-2758-9399; Woo-Jung Park: http://orcid.org/0000-0001-66930364; Sung Han Park: http://orcid.org/0000-0003-4540-0115; Bo Youl Choi: $h t t p: / / o r c i d . o r g / 0000-0003-0115-5736$; Sung Soon Kim: http://orcid.org/0000-0003-2774-6710; Moran Ki: http://orcid.org/ 0000-0002-8892-7104

\section{REFERENCES}

1. de Groot RJ, Baker SC, Baric RS, Brown CS, Drosten C, Enjuanes $\mathrm{L}$, et al. Middle East respiratory syndrome coronavirus (MERS$\mathrm{CoV}$ ): announcement of the Coronavirus Study Group. J Virol 2013;87:7790-7792.

2. van Boheemen S, de Graaf M, Lauber C, Bestebroer TM, Raj VS, Zaki AM, et al. Genomic characterization of a newly discovered coronavirus associated with acute respiratory distress syndrome in humans. MBio 2012;3:e00473-12.

3. Zaki AM, van Boheemen S, Bestebroer TM, Osterhaus AD, Fouchier RA. Isolation of a novel coronavirus from a man with pneumonia in Saudi Arabia. N Engl J Med 2012;367:1814-1820.

4. Assiri A, Al-Tawfiq JA, Al-Rabeeah AA, Al-Rabiah FA, Al-Hajjar S, Al-Barrak A, et al. Epidemiological, demographic, and clinical characteristics of 47 cases of Middle East respiratory syndrome coronavirus disease from Saudi Arabia: a descriptive study. Lancet Infect Dis 2013;13:752-761.

5. Al-Tawfiq JA, Hinedi K, Ghandour J, Khairalla H, Musleh S, Ujayli A, et al. Middle East respiratory syndrome coronavirus: a casecontrol study of hospitalized patients. Clin Infect Dis 2014;59:160165.

6. Assiri A, McGeer A, Perl TM, Price CS, Al Rabeeah AA, Cummings DA, et al. Hospital outbreak of Middle East respiratory syndrome coronavirus. N Engl J Med 2013;369:407-416.

7. Al-Tawfiq JA, Memish ZA. Middle East respiratory syndrome coronavirus: epidemiology and disease control measures. Infect Drug Resist 2014;7:281-287.

8. Al-Abdallat MM, Payne DC, Alqasrawi S, Rha B, Tohme RA, Abedi GR, et al. Hospital-associated outbreak of Middle East respiratory syndrome coronavirus: a serologic, epidemiologic, and clinical description. Clin Infect Dis 2014;59:1225-1233.

9. Choi JW, Kim KH, Cho YM, Kim SH. Current epidemiological situation of Middle East respiratory syndrome coronavirus clusters and implications for public health response in South Korea. J Korean Med Assoc 2015;58:487-497 (Korean).

10. Memish ZA, Al-Tawfiq JA. Middle East respiratory syndrome coronavirus infection control: the missing piece? Am J Infect Control 2014;42:1258-1260.

11. Ki M. 2015 MERS outbreak in Korea: hospital-to-hospital transmission. Epidemiol Health 2015:37:e2015033.

12. World Health Organization. Middle East respiratory syndrome coronavirus (MERS-CoV) - update; 2014 Jun 13 [cited 2016 May 30]. Available from: http://www.who.int/csr/don/2014_06_13_ 
mers/en/.

13. World Health Organization. Middle East respiratory syndrome coronavirus (MERS-CoV) - update; 2014 Jun 26 [cited 2016 May 31]. Available from: http://www.who.int/csr/don/2014_06_26/en/.

14. Oboho IK, Tomczyk SM, Al-Asmari AM, Banjar AA, Al-Mugti H, Aloraini MS, et al. 2014 MERS-CoV outbreak in Jeddah--a link to health care facilities. N Engl J Med 2015;372:846-854.

15. Park GE, Ko JH, Peck KR, Lee JY, Lee JY, Cho SY, et al. Control of an outbreak of Middle East respiratory syndrome in a tertiary hospital in Korea. Ann Intern Med 2016;165:87-93.

16. Kim CJ, Choi WS, Jung Y, Kiem S, Seol HY, Woo HJ, et al. Surveillance of the Middle East respiratory syndrome (MERS) coronavirus $(\mathrm{CoV})$ infection in healthcare workers after contact with confirmed MERS patients: incidence and risk factors of MERSCoV seropositivity. Clin Microbiol Infect 2016;22:880-886.

17. Gossner C, Danielson N, Gervelmeyer A, Berthe F, Faye B, Kaasik Aaslav K, et al. Human-dromedary camel interactions and the risk of acquiring zoonotic Middle East respiratory syndrome coronavirus infection. Zoonoses Public Health 2016;63:1-9.

18. Al Hammadi ZM, Chu DK, Eltahir YM, Al Hosani F, Al Mulla M, Tarnini W, et al. Asymptomatic MERS-CoV infection in humans possibly linked to infected camels imported from Oman to United Arab Emirates, May 2015. Emerg Infect Dis 2015;21:2197-2200.

19. Hemida MG, Al-Naeem A, Perera RA, Chin AW, Poon LL, Peiris M. Lack of Middle East respiratory syndrome coronavirus transmission from infected camels. Emerg Infect Dis 2015;21:699-701.

20. Jeong H, Yim HW, Song YJ, Ki M, Min JA, Cho J, et al. Mental health status of people isolated due to Middle East Respiratory Syndrome. Epidemiol Health 2016;38:e2016048.

21. Kim SW, Park JW, Jung HD, Yang JS, Park YS, Lee C, et al. Risk factors for transmission of Middle East respiratory syndrome coronavirus infection during the 2015 outbreak in South Korea. Clin Infect Dis 2017;64:551-557.

22. Cohen BJ, Audet S, Andrews N, Beeler J, WHO working group on measles plaque reduction neutralization test. Plaque reduction neutralization test for measles antibodies: description of a standardised laboratory method for use in immunogenicity studies of aerosol vaccination. Vaccine 2007;26:59-66.

23. Park YS, Lee C, Kim KM, Kim SW, Lee KJ, Ahn J, et al. The first case of the 2015 Korean Middle East Respiratory Syndrome out- break. Epidemiol Health 2015;37:e2015049.

24. Kim KM, Ki M, Cho SI, Sung M, Hong JK, Cheong HK, et al. Epidemiologic features of the first MERS outbreak in Korea: focus on Pyeongtaek St. Mary's Hospital. Epidemiol Health 2015;37: e2015041.

25. Müller MA, Meyer B, Corman VM, Al-Masri M, Turkestani A, Ritz D, et al. Presence of Middle East respiratory syndrome coronavirus antibodies in Saudi Arabia: a nationwide, cross-sectional, serological study. Lancet Infect Dis 2015;15:629.

26. Memish ZA, Zumla AI, Al-Hakeem RF, Al-Rabeeah AA, Stephens GM. Family cluster of Middle East respiratory syndrome coronavirus infections. N Engl J Med 2013;368:2487-2494.

27. Memish ZA, Al-Tawfiq JA, Makhdoom HQ, Al-Rabeeah AA, Assiri A, Alhakeem RF, et al. Screening for Middle East respiratory syndrome coronavirus infection in hospital patients and their healthcare worker and family contacts: a prospective descriptive study. Clin Microbiol Infect 2014;20:469-474.

28. Yoo W, Choi DH, Park K. The effects of SNS communication: how expressing and receiving information predict MERS-preventive behavioral intentions in South Korea. Comput Human Behav 2016;62:34-43.

29. McNab C. What social media offers to health professionals and citizens. Bull World Health Organ 2009;87:566.

30. Bauch CT, Oraby T. Assessing the pandemic potential of MERSCoV. Lancet 2013;382:662-664.

31. Breban R, Riou J, Fontanet A. Interhuman transmissibility of Middle East respiratory syndrome coronavirus: estimation of pandemic risk. Lancet 2013;382:694-699.

32. Lee C, Ki M. Strengthening epidemiologic investigation of infectious diseases in Korea: lessons from the Middle East Respiratory Syndrome outbreak. Epidemiol Health 2015;37:e2015040.

33. Park WB, Perera RA, Choe PG, Lau EH, Choi SJ, Chun JY, et al. Kinetics of serologic responses to MERS coronavirus infection in humans, South Korea. Emerg Infect Dis 2015;21:2186-2189.

34. Payne DC, Iblan I, Rha B, Alqasrawi S, Haddadin A, Al Nsour M, et al. Persistence of antibodies against Middle East respiratory syndrome coronavirus. Emerg Infect Dis 2016;22:1824-1826.

35. Cao WC, Liu W, Zhang PH, Zhang F, Richardus JH. Disappearance of antibodies to SARS-associated coronavirus after recovery. N Engl J Med 2007;357:1162-1163. 